\title{
Common themes and unique proteins for the uptake and trafficking of nickel, a metal essential for the virulence of Helicobacter pylori
}

\author{
Hilde de Reuse ${ }^{1 *}$, Daniel Vinella ${ }^{1}$ and Christine Cavazza ${ }^{2}$ \\ 1 Unité Pathogenèse de Helicobacter, Département de Microbiologie, Institut Pasteur, ERL CNRS 3526, Paris, France \\ ${ }^{2}$ Metalloproteins Group, Institut de Biologie Structurale Jean-Pierre Ebel, UMR 5075, CEA, CNRS, Université Joseph Fourier-Grenoble 1, Grenoble, France
}

Edited by:

Frédéric J. Veyrier, Institut Pasteur,

France

\section{Reviewed by:}

David Pignol, Commissariat à

l'énergie Atomique, France

Alberto Danielli, University of

Bologna, Italy

Wolfgang Fischer, Max von

Pettenkofer-Institut der

Ludwig-Maximilians-Universitaet

Germany

\section{*Correspondence:}

Hilde de Reuse, Unité Pathogenèse de Helicobacter, Département de

Microbiologie, Institut Pasteur, ERL

CNRS 3526, 28 Rue du Docteur

Roux, 75724 Paris, France

e-mail: hdereuse@pasteur.fr
Nickel is a virulence determinant for the human gastric pathogen Helicobacter pylori. Indeed, H. pylori possesses two nickel-enzymes that are essential for in vivo colonization, [NiFe] hydrogenase and urease, an abundant virulence factor that contains 24 nickel ions per active complex. Because of these two enzymes, survival of $H$. pylori relies on an important supply of nickel, implying a tight control of its distribution and storage. In this review, we will present the pathways of activation of the nickel enzymes as well as original mechanisms found in $\mathrm{H}$. pylori for the uptake, trafficking and distribution of nickel between the two enzymes. These include (i) an outer-membrane nickel uptake system, the FrpB4 TonB-dependent transporter, (ii) overlapping protein complexes and interaction networks involved in nickel trafficking and distribution between urease and hydrogenase and, (iii) Helicobacter specific nickel-binding proteins that are involved in nickel storage and can play the role of metallo-chaperones. Finally, we will discuss the implication of the nickel trafficking partners in virulence and propose them as novel therapeutic targets for treatments against $H$. pylori infection.

Keywords: nickel, urease maturation, hydrogenase, Helicobacter pylori, metal trafficking

\section{INTRODUCTION}

For many organisms, acquisition of essential metal ions that are present at low concentrations in their environment is a critical process. Once acquired, the correct metal has to be delivered and incorporated into specific target enzymes through dedicated protein complexes comprising chaperones and so-called accessory proteins and when in excess the metals have to be stored as their non-physiological high intracellular concentrations are toxic.

The proteins involved in import, cellular storage, distribution, and incorporation of metal ions into enzymes are collectively referred to as "metal trafficking proteins". In bacteria, tremendous efforts have been devoted to decipher the mechanisms of iron uptake, trafficking and intracellular homeostasis control. Much less information is available for the acquisition and homeostasis of nickel, which is nevertheless an essential element for several bacteria. Nickel is the cofactor of at least nine enzymes involved in diverse cellular processes such as energy metabolism or virulence, including [ $\mathrm{NiFe}]$-hydrogenase, urease, Ni-SOD, COdehydrogenase (Higgins et al., 2012; Boer et al., 2013). Nickel is ubiquitously found in the environment and present at low concentrations in vertebrates. Although no enzymes or co-factors that include nickel were identified in higher organisms so far, animal experiments with nickel-deficient diets suggest a physiological role for nickel in these organisms (Denkhaus and Salnikow, 2002). It is tempting to speculate that nickel is required in higher organisms to sustain growth of the microbiote. Finally, different mechanisms have been proposed to explain cellular nickel toxicity, among which replacement by nickel of the metal of essential metalloproteins or indirect generation of oxidative stress (Macomber and Hausinger, 2011).

As for iron, specific and controlled nickel transport, efflux and trafficking processes are necessary as well as specific nickel storage proteins and nickel-responsive transcriptional regulators (such as NikR, for a review see Dosanjh et al., 2009). The gastric pathogen Helicobacter pylori presents interesting nickel management strategies, some being common to other bacteria and others being unique to this organism (Figure 1). H. pylori is therefore a fascinating model organism to study nickel uptake and trafficking as well as the link between virulence and these pathways. These aspects will be discussed in this mini-review.

\section{NICKEL, A VIRULENCE DETERMINANT FOR Helicobacter pylori}

H. pylori is a gram-negative bacterial pathogen of major importance that colonizes the stomach of about half of the human population worldwide. Gastric infection by $H$. pylori causes gastritis and peptic ulcer disease. In addition, decades of persistent infection by $H$. pylori favors the development of gastric cancer (Wroblewski et al., 2010). H. pylori, is until now the sole bacterium recognized as a class I carcinogen and causes 800,000 deaths worldwide annually. It is the only bacterium that can multiply in the stomach, a hostile acid niche (median $\mathrm{pH}$ 2). Nickel can be regarded as a virulence determinant for $\mathrm{H}$. pylori since it is the co-factor of urease, an enzyme essential for resistance to acidity. Urease is a major virulence factor essential for colonization of animal models. [NiFe] hydrogenase, the only other nickel-enzyme 


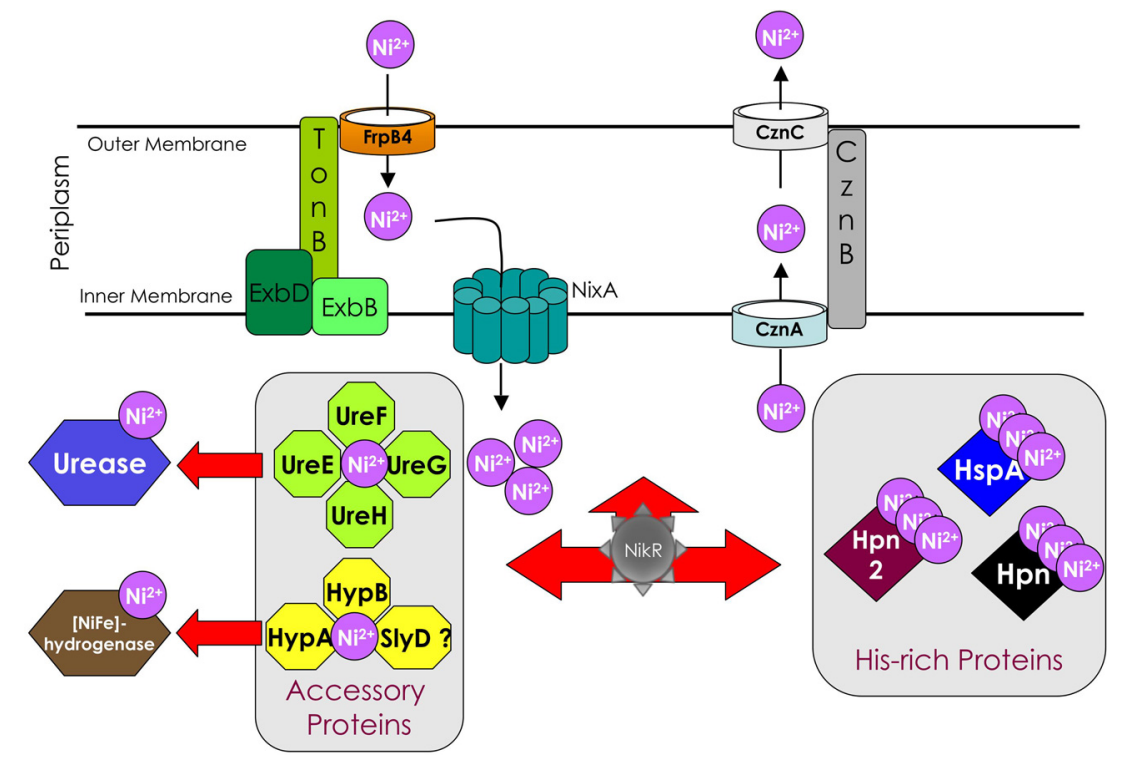

FIGURE 1 | Schematic representation of the Helicobacter pylori major components involved in nickel uptake, efflux, trafficking and incorporation into the two nickel metalloenzymes urease and [NiFe] hydrogenase and of the nickel-responsive transcriptional regulator NikR.

found in $H$. pylori is important for murine colonization probably because it enables the use of $\mathrm{H}_{2}$ as an energy source. Urease represents $6-10 \%$ of total $H$. pylori proteins. In addition, we measured a total intracellular nickel concentration of approximately $60 \mathrm{nM}$ in H. pylori, corresponding to 50 times that of Escherichia coli (Schauer, 2007). Thus, a constant and important supply of nickel is required for the survival of $H$. pylori within the stomach, implying a tight control of its acquisition, distribution and storage. The properties of urease and hydrogenase will be briefly presented followed by the description of the nickel trafficking pathways.

\section{UREASE AND HYDROGENASE UREASE}

Urease catalyzes the hydrolysis of urea to produce ammonia and carbamate, the latter being spontaneously degraded into a second molecule of ammonia and bicarbonate (Boer et al., 2013). These compounds act as buffers to maintain a neutral cytosolic $\mathrm{pH}$ in H. pylori (Stingl and De Reuse, 2005). The first crystal structure of a bacterial urease, from Klebsiella aerogenes, revealed a dinuclear nickel active site deeply buried in the alpha subunits (Jabri et al., 1995). The two nickel ions are bound to the protein via two histidines (His), an aspartate and a bridging carboxylate group of a carbamylated lysine. The $H$. pylori urease is composed of the UreA and UreB subunits. Its structure has also been solved (Ha et al., 2001) revealing a giant 1.1-MDa dodecameric complex (four trimers of UreA-B heterodimers) containing as much as 24 nickel ions. This enzyme has the highest affinity to its substrate ever described for a urease.

\section{HYDROGENASE}

[NiFe]-hydrogenases catalyze the reversible heterolytic cleavage of dihydrogen. The active site, buried in the large subunit of a heterodimeric protein, contains a $\mathrm{Fe}(\mathrm{CO})(\mathrm{CN})_{2}$ unit and a nickel ion (Fontecilla-Camps et al., 2007). Protein coordination is mediated by two Fe-Ni bridging and two nickel-binding terminal Cys thiolates (Volbeda et al., 1995). The catalytic nickel ion has both a terminal coordination site and a bridging coordination site. H. pylori possesses a membrane-bound respiratory [NiFe] hydrogenase (Maier et al., 1996) that catalyzes the oxidation of dihydrogen. It is important for colonization of the mouse model possibly because dihydrogen, a fermentation by-product of the gut microorganisms, is used by $H$. pylori as an energy substrate (Olson and Maier, 2002; Maier, 2005).

\section{IN VIVO UREASE ACTIVATION AND ACCESSORY PROTEIN COMPLEXES}

In vivo activation of urease requires dedicated accessory proteins that function through protein complexes to help the specific incorporation of nickel at the right site in a coordinated manner (Carter et al., 2009). In H. pylori, the ureA-ureB structural genes are followed by the accessory gene cluster ureEFGH. Using Tandem Affinity Purification, we isolated from $H$. pylori cells a complex comprising UreA-B and the complete activation complex UreH-UreF-UreG-UreE (Stingl et al., 2008). A computational model of this complex was recently proposed (Biagi et al., 2013).

UreE is a nickel metallochaperone that interacts with UreG (Bellucci et al., 2009). UreG is an intrinsically unstructured GTPase that dimerizes upon binding of a metal ion (Zambelli et al., 2005, 2009; Musiani et al., 2013). It has been suggested that binding of the UreF-UreH complex induces conformational changes in urease, allowing nickel ion and carbon dioxide to access the active site. UreF was shown to gate the GTPase activity of UreG to enhance the fidelity of urease metallocenter assembly (Boer and Hausinger, 2012). A recent crystal structure of the H. pylori UreG-UreF-UreH complex reveals how UreF and UreH 
facilitate UreG dimerization and how it assembles its metal binding site (Fong et al., 2013). The addition of nickel and GTP to the UreG-UreF-UreH complex causes release of the UreG dimer that binds nickel at the dimeric interface. In vitro, nickel-charged UreG dimer was shown to activate urease in the presence of UreF/UreH. How nickel is transferred from UreE to the binding site of UreG and how the complete activation complex interacts with urease has still to be determined.

\section{IN VIVO HYDROGENASE ACTIVATION AND INTERCONNECTIVITY BETWEEN THE UREASE AND HYDROGENASE MATURATION PATHWAYS IN $\boldsymbol{H}$. pylori}

[NiFe] hydrogenase activation by nickel incorporation also requires dedicated accessory proteins that are conserved in $H$. pylori (Leach and Zamble, 2007; Maier et al., 2007). HypCDEF are necessary for the synthesis and correct insertion of the $\mathrm{Fe}(\mathrm{CO})(\mathrm{CN})_{2}$ moiety in apo-hydrogenase. Once the iron center gets assembled and inserted, nickel is delivered to the enzyme through the concerted action of the metallo-chaperone HypA and the GTPase HypB that were characterized in H. pylori (Xia et al., 2012). In E. coli, the nickel-binding protein SlyD is an essential additional partner of hydrogenase maturation, presumably involved in stimulating the release of nickel from HypB (Leach et al., 2007).

A unique particularity of nickel trafficking in $H$. pylori is the interconnectivity between the urease and hydrogenase maturation pathways. Indeed, $H$. pylori mutant characterization revealed that HypA and HypB are required not only for hydrogenase maturation but also for full urease activation (Olson et al., 2001). In agreement with this, our $H$. pylori interactome analysis evidenced that HypB is physically associated to the urease maturation complex (Stingl et al., 2008). This interactome also contained SlyD (Stingl et al., 2008) shown to interact with HypB in vitro and in vivo in E. coli (Cheng et al., 2013). However, the role of SlyD in H. pylori cells and in urease/hydrogenase activities remains unclear. Benanti and Chivers (2009) showed that in H. pylori strain 26695, urease activity was strongly diminished in a double $\Delta s l y D / \triangle h y p A$ mutant as compared to a single $\Delta h y p A$ mutant, but this effect was not observed in strain G27. While SlyD may serve as a nickel reservoir to activate urease, the properties of nickel storage proteins might differ depending on the $H$. pylori genetic context. To be mentioned, in the closely related organism Campylobacter jejuni, hydrogenase activity is not modified in a $\Delta$ slyD mutant (Howlett et al., 2012).

Using optical-biosensing methods, it was found that the $H$. pylori HypA and UreG proteins compete with each other for UreE recognition, suggesting that the function of HypA in urease activation relies on nickel delivery or exchange rather than on catalytic activities (Benoit et al., 2012). Indeed, purified recombinant HypA is sufficient for the recovery of urease activity in H. pylori cell lysates from a hypA deletion mutant (Herbst et al., 2010). This can be related to the observation that unlike many of its orthologs, the H. pylori UreE dimer only binds one equivalent of $\mathrm{Ni}^{2+}$ (Bellucci et al., 2009).

While the accessory proteins for both urease and hydrogenase maturation are conserved in $H$. pylori, several particularities of nickel trafficking in this organism have emerged. At least three nickel-binding proteins have important functions in nickel trafficking in $H$. pylori and a novel nickel uptake system was discovered. We believe that $H$. pylori acquired these additional partners to deal with its exceptionally high intracellular nickel concentration, the fluctuating nickel availability and $\mathrm{pH}$ in the stomach and with a critical need to coordinate nickel distribution between two essential enzymes.

\section{NICKEL TRANSPORT AND EFFLUX}

In Gram-negative bacteria, energized transport of metabolites such as iron-siderophore complexes through the outer membrane (OM) relies on the TonB machinery and on TonB-dependenttransporters (TBDTs). The first nickel transport system across a bacterial OM was described in H. pylori by our group (Schauer et al., 2007). Its expression is repressed by NikR in the presence of nickel. This transport requires the FrpB4 TBDT and is acidinduced, allowing $H$. pylori to optimize urease activity by nickel incorporation under conditions where urease activity needs to be maximal. Additional mechanisms certainly exist allowing, for example, nickel entry at neutral $\mathrm{pH}$. FecA3, another $H$. pylori TBDT whose synthesis is under nickel control (Romagnoli et al., 2011), is probably an alternative nickel-uptake system (Ernst et al., 2006). It is not clear under which form nickel is recognized by the TBDT. By analogy with siderophores, it is possible that a nickelophore, i.e., a small organic chelator of nickel, is required for its transport. A nickelophore was shown to be required for nickel binding into the $E$. coli NikA protein: it can be either a small organic ligand (Cherrier et al., 2008) or a (L-His) 2 (Chivers et al., 2012; Lebrette et al., 2013).

In H. pylori, nickel transport across the cytoplasmic membrane can be mediated by NixA, a high-affinity and low-capacity nickel transporter (Fulkerson and Mobley, 2000) of the NiCoT family, which expression is repressed by nickel (Wolfram et al., 2006). As a NixA mutant retains half of urease activity and is still able to colonize the mouse model (Nolan et al., 2002), alternative ways of nickel entry must exist. Other Helicobacter species present different combinations of similar nickel transport systems. In Helicobacter mustelae, nickel uptake and urease activation depend on NikH, a TBDT different from FrpB4 (Stoof et al., 2010b) and on the FecDE/CeuE ABC transport system (Stoof et al., 2010a). Helicobacter hepaticus possesses genes regulated by NikR that are homologous to those encoding the $E$. coli nickel $\mathrm{ABC}$ transporter and to nikH of $H$. mustelae (Benoit et al., 2013b). The fecDE/ceuE genes are conserved in H. pylori and might be an additional nickel transport system across the inner membrane.

Again, the possible variety in nickel uptake mechanisms underscores the utmost importance of nickel uptake in $H$. pylori and closely related Helicobacter species.

Having crossed the inner membrane, nickel has to be directed to its proper targets while avoiding potential damages caused by free metal ions. If nickel is in excess with respect to $H$. pylori cellular needs, it must either be stored or exported from the cell. Only one nickel export system has been described in H. pylori, a proton-driven RND-type metal efflux-pump encoded by the $c z n A B C$ genes. Inactivation of this pump increases H. pylori sensitivity to nickel, cadmium and zinc and impairs colonization of the gerbil stomach (Stahler et al., 2006), underlining the importance of metal homeostasis for $H$. pylori virulence. 


\section{UNUSUAL NICKEL CHAPERONES AND STORAGE PROTEINS IN H. pylori}

In H. pylori, HspA is the sole member of the highly conserved and essential GroES co-chaperonine family (Suerbaum et al., 1994). The $h s p A$ gene transcription is activated by NikR with nickel (Muller et al., 2011). HspA protein is particular by the fact that it contains a His- and Cys-rich C-terminal extension that was shown to bind nickel ions in vitro (Kansau et al., 1996). Deletion of this extension is viable and impairs the maturation of hydrogenase but not that of urease (Schauer et al., 2010). We concluded that HspA could constitute a nickel storage pool specifically used for hydrogenase maturation. How nickel is mobilized from HspA and whether HspA provides nickel to other proteins remain to be determined. A more general role of HspA in nickel storage/detoxification is suggested by its abundance and by the fact that deletion of its C-terminal extension decreases the intracellular nickel content and increases nickel sensitivity (Schauer et al., 2010).

H. pylori also possesses two proteins of remarkable amino-acid composition that are conserved in $H$. pylori and have no orthologs outside the Helicobacter species. Hpn and Hpn-2 (or Hpn-like) are two small proteins $(7$ and $8 \mathrm{kDa}$ ) that are extremely rich in His-residues: 47 and $25 \%$ of the total residues, respectively. Hpn2 contains additional poly-Glutamine stretches representing 40\% of the total residues. These two proteins were shown in vitro to bind nickel and to form multimers (Gilbert et al., 1995; Ge et al., 2006; Rowinska-Zyrek et al., 2011; Zeng et al., 2008, 2011). Like $h s p A$, transcription of these genes is upregulated by NikR with nickel (Muller et al., 2011). Because $h p n$ and $h p n-2$ mutants were found to be more sensitive to high exogenous nickel concentrations than a wild type strain, these abundant proteins were suggested to be involved in nickel storage and detoxification via sequestration of excess nickel (Mobley et al., 1999; Seshadri et al., 2007). Seshadri et al. (2007) reported that both proteins compete with the nickel-dependent urease maturation machinery under low nickel conditions. However, previous data showed wild-type urease activity in a $h p n$ deletion mutant (Gilbert et al., 1995). While Hpn and Hpn-2 proteins are certainly central in the nickel trafficking pathways of $H$. pylori and are possibly directly or indirectly involved in urease activation, their respective roles in these processes remain to be established. Recently, purified Hpn was shown to form in vitro amyloïd-like fibrils that are toxic when applied to cultured gastric epithelial cells (Ge et al., 2011). The existence and function of these fibers and the effect of nickel on their formation has yet to be demonstrated in vivo.

\section{UREASE, NICKEL, AND VIRULENCE}

The two nickel metalloenzymes (urease and [NiFe] hydrogenase) are determinant in $H$. pylori colonization capacity. In addition to its role in acid resistance, urease fuels $H$. pylori with ammonium for nitrogen assimilation (Williams et al., 1996). The produced ammonia is cytotoxic either alone or in conjunction with neutrophil metabolites (Sommi et al., 1996). Urease activity is also important for survival into macrophages, evasion from phagocytosis, and complement-mediated opsonisation. Purified urease protein stimulates activation of macrophages, dysregulates tightjunctions and induces cytokine production from gastric epithelial cells. These effects might be related to the large amounts of urease-bound nickel delivered to the host cells, considering the 24 nickel ions per active urease complex.

H. pylori displays a chemotactic repulsive response to nickel that might help its orientation during stomach colonization (Sanders et al., 2013). In addition, using a mouse model fed with Ni-deficient chow, a weak colonization defect was observed with the double $\Delta h p n-\Delta h p n-2$ mutant (Benoit et al., 2013a). This suggests a role of Hpn and/or Hpn-2 in nickel incorporation during host colonization. Incubation of gastric epithelial cells with purified recombinant $H$. pylori SlyD protein disturbs cell proliferation, apoptosis, and enhances cell transformation and invasion (Kang et al., 2013). It was thus proposed that SlyD contributes to the gastric pathogenicity of $H$. pylori. Further studies with slyD-deficient strains are needed to establish the role of SlyD in vivo. Finally, purified recombinant HspA protein induces the expression of pro-inflammatory cytokines in human cells (Lin et al., 2006). Here again, nickel delivery to hosts cells mediated by nickel-binding proteins might cause these effects.

\section{CONCLUSION}

H. pylori possesses original properties for nickel uptake and trafficking that are directly related to its virulence and reflect the absolute need for this organisms to manage high nickel concentrations. Some of the factors that were discovered in H. pylori seem to be present in other organisms (nickel TBDTs in other Helicobacter species) and such transporters are predicted in other species (Schauer et al., 2008).

Several fascinating questions remain to be answered. Are the functions of Hpn and Hpn-2 proteins restricted to nickel storage or do they constitute urease-dedicated $H$. pylori chaperones? How large is the variety of nickel transporters? Are there nickelophores needed for nickel uptake and, if so, is this nickelophore synthesized by $H$. pylori or acquired from the environment? Given the properties of $H$. pylori and the absence of nickel-enzymes in the human body, it is tempting to propose the nickel trafficking pathways of $H$. pylori as targets for the development of alternative antibacterial drugs.

\section{ACKNOWLEDGMENTS}

We would like to thank Frédéric Fischer from the Unité de Pathogenèse de Helicobacter for his careful and constructive comments and corrections on this mini-review and Julien Gallaud for the figure. We thank Janssen for financial support.

\section{REFERENCES}

Bellucci, M., Zambelli, B., Musiani, F., Turano, P. and Ciurli, S. (2009). Helicobacter pylori UreE, a urease accessory protein: specific $\mathrm{Ni}^{2+}$ - and $\mathrm{Zn}^{2+}$-binding properties and interaction with its cognate UreG. Biochem. J. 422, 91-100. doi: 10.1042/BJ20090434

Benanti, E. L. and Chivers, P. T. (2009). An intact urease assembly pathway is required to compete with NikR for nickel ions in Helicobacter pylori. J. Bacteriol. 191, 2405-2408. doi: 10.1128/JB.01657-08

Benoit, S. L., McMurry, J. L., Hill, S. A. and Maier, R. J. (2012). Helicobacter pylori hydrogenase accessory protein $\mathrm{HypA}$ and urease accessory protein UreG compete with each other for UreE recognition. Biochim. Biophys. Acta 1820, 1519-1525. doi: 10.1016/j.bbagen.2012. 06.002 
Benoit, S. L., Miller, E. F. and Maier, R. J. (2013a). Helicobacter pylori stores nickel to aid its host colonization. Infect Immun. 81, 580-584. doi: 10.1128/IAI.00858-12

Benoit, S. L., Seshadri, S., Lamichhane-Khadka, R. and Maier, R. J. (2013b). Helicobacter hepaticus NikR controls urease and hydrogenase activities via the NikABDE and HH0418 putative nickel import proteins. Microbiology 159, 136-146. doi: 10.1099/mic.0.062976-0

Biagi, F., Musiani, F. and Ciurli, S. (2013). Structure of the UreD-UreF-UreG-UreE complex in Helicobacter pylori: a model study. J. Biol. Inorg. Chem. 18, 571-577. doi: 10.1007/s00775-013-1002-8

Boer, J. L. and Hausinger, R. P. (2012). Klebsiella aerogenes UreF: identification of the UreG binding site and role in enhancing the fidelity of urease activation. Biochemistry 51, 2298-2308. doi: 10.1021/bi3000897

Boer, J. L., Mulrooney, S. B. and Hausinger, R. P. (2013). Nickel-dependent metalloenzymes. Arch. Biochem. Biophys. doi: 10.1016/j.abb.2013.09.002. [Epub ahead of print].

Carter, E. L., Flugga, N., Boer, J. L., Mulrooney, S. B. and Hausinger, R. P. (2009). Interplay of metal ions and urease. Metallomics 1, 207-221. doi: 10.1039/b903311d

Cheng, T., Li, H., Yang, X., Xia, W. and Sun, H. (2013). Interaction of SlyD with HypB of Helicobacter pylori facilitates nickel trafficking. Metallomics 5, 804-807. doi: $10.1039 / \mathrm{c} 3 \mathrm{mt} 00014 \mathrm{a}$

Cherrier, M. V., Cavazza, C., Bochot, C., Lemaire, D. and Fontecilla-Camps, J. C. (2008). Structural characterization of a putative endogenous metal chelator in the periplasmic nickel transporter NikA. Biochemistry 47, 9937-9943. doi: 10.1021/bi801051y

Chivers, P. T., Benanti, E. L., Heil-Chapdelaine, V., Iwig, J. S. and Rowe, J. L. (2012). Identification of Ni-(L-His) ${ }_{2}$ as a substrate for NikABCDE-dependent nickel uptake in Escherichia coli. Metallomics 4, 1043-1050. doi: 10.1039/c2mt 20139a

Denkhaus, E. and Salnikow, K. (2002). Nickel essentiality, toxicity, and carcinogenicity. Crit. Rev. Oncol. Hematol. 42, 35-56. doi: 10.1016/S10408428(01)00214-1

Dosanjh, N. S., West, A. L. and Michel, S. L. J. (2009). Helicobacter pylori NikR's Interaction with DNA: a two-tiered mode of recognition. Biochemistry 48, 527-536. doi: 10.1021/bi801481j

Ernst, F. D., Stoof, J., Horrevoets, W. M., Kuipers, E. J., Kusters, J. G. and van Vliet, A. H. M. (2006). NikR mediates nickel-responsive transcriptional repression of the Helicobacter pylori outer membrane proteins FecA3 (HP1400) and FrpB4 (HP1512). Infect. Immun. 74, 6821-6828. doi: 10.1128/IAI.01196-06

Fong, Y. H., Wong, H. C., Yuen, M. H., Lau, P. H., Chen, Y. W. and Wong, K. B. (2013). Structure of UreG/UreF/UreH complex reveals how urease accessory proteins facilitate maturation of Helicobacter pylori Urease. PLoS Biol. 11:e1001678. doi: 10.1371/journal.pbio.1001678

Fontecilla-Camps, J. C., Volbeda, A., Cavazza, C. and Nicolet, Y. (2007). Structure/function relationships of $[\mathrm{NiFe}]-$ and $[\mathrm{FeFe}]$-hydrogenases. Chem. Rev. 107, 4273-4303. doi: 10.1021/cr050195z

Fulkerson, J. F. and Mobley, H. L. T. (2000). Membrane topology of the NixA nickel transporter of Helicobacter pylori: two nickel transport-specific motifs within transmembrane helices II and III. J. Bacteriol. 182, 1722-1730. doi: 10.1128/JB.182.6.1722-1730.2000

Ge, R. G., Watt, R. M., Sun, X. S., Tanner, J. A., He, Q. Y., Huang, J. D. and Sun, H. Z. (2006). Expression and characterization of a histidine-rich protein, Hpn: potential for Ni2+ storage in Helicobacter pylori. Biochem. J. 393, 285-293. doi: 10.1042/BJ20051160

Ge, R., Sun, X., Wang, D., Zhou, Q. and Sun, H. (2011). Histidine-rich protein Hpn from Helicobacter pylori forms amyloid-like fibrils in vitro and inhibits the proliferation of gastric epithelial AGS cells. Biochim. Biophys. Acta 1813, 1422-1427. doi: 10.1016/j.bbamcr.2011.04.005

Gilbert, J. V., Ramakrishna, J., Sunderman, F. W., Wright, A. and Plaut, A. G. (1995). Protein Hpn: cloning and characterization of a histidine-rich metal-binding polypeptide in Helicobacter pylori and Helicobacter mustelae. Infect. Immun. 63, 2682-2688.

Ha, N. C., Oh, S. T., Sung, J. Y., Cha, K. A., Lee, M. H. and Oh, B. H. (2001). Supramolecular assembly and acid resistance of Helicobacter pylori urease. Nat. Struct. Biol. 8, 505-509. doi: 10.1038/88563

Herbst, R. W., Perovic, I., Martin-Diaconescu, V., O’Brien, K., Chivers, P. T., Pochapsky, S. S., et al. (2010). Communication between the Zinc and Nickel Sites in Dimeric HypA: metal recognition and $\mathrm{pH}$ sensing. J. Am. Chem. Soc. 132, 10338-10351. doi: 10.1021/ja1005724
Higgins, K. A., Carr, C. E. and Maroney, M. J. (2012). Specific metal recognition in nickel trafficking. Biochemistry 51, 7816-7832. doi: 10.1021/bi300981m

Howlett, R., Hughes, B., Hitchcock, A. and Kelly, D. J. (2012). Hydrogenase activity in the foodborne pathogen Campylobacter jejuni depends upon a novel ABCtype nickel transporter (NikZYXWV) and is SlyD-independent. Microbiology 158, 1645-1655. doi: 10.1099/mic.0.054130-0

Jabri, E., Carr, M. B., Hausinger, R. P. and Karplus, P. A. (1995). The crystal structure of urease from Klebsiella aerogenes. Science 268, 998-1004. doi: 10.1126/science.7754395

Kang, D., Gong, Y., Zhu, Y., Li, A., Dong, N., Piao, Y. and Yuan, Y. (2013). The biological activity of $H$. pylori SlyD in vitro. Helicobacter. 18, 347-355. doi: 10.1111/hel.12057

Kansau, I., Guillain, F., Thiberge, J.-M. and Labigne, A. (1996). Nickel binding and immunological properties of the C-terminal domain of the Helicobacter pylori GroES homologue (HspA). Mol. Microbiol. 22, 1013-1023. doi: 10.1046/j.13652958.1996.01536.x

Leach, M. R., Zhang, J. W. and Zamble, D. B. (2007). The role of complex formation between the Escherichia coli hydrogenase accessory factors HypB and SlyD. J. Biol. Chem. 282, 16177-16186. doi: 10.1074/jbc.M610834200

Leach, M. R. and Zamble, D. B. (2007). Metallocenter assembly of the hydrogenase enzymes. Curr. Opin. Chem. Biol. 11, 159-165. doi: 10.1016/j.cbpa.2007.01.011

Lebrette, H., Iannello, M., Fontecilla-Camps, J. C., and Cavazza, C. (2013). The binding mode of $\mathrm{Ni}-(\mathrm{L}-\mathrm{His}) 2$ in NikA revealed by X-ray crystallography. J. Inorg. Biochem. 121, 16-18. doi: 10.1016/j.jinorgbio.2012.12.010

Lin, Y. F., Wu, M. S., Chang, C. C., Lin, S. W., Lin, J. T., Sun, Y. J., et al. (2006). Comparative immunoproteomics of identification and characterization of virulence factors from Helicobacter pylori related to gastric cancer. Mol. Cell Proteom. 5, 1484-1496.

Macomber, L. and Hausinger, R. (2011). Mechanisms of nickel toxicity in microorganisms. Metallomics 3, 1153-1162. doi: 10.1039/c1mt00063b

Maier, R. J. (2005). Use of molecular hydrogen as an energy substrate by human pathogenic bacteria. Biochem. Soc. Trans. 33, 83-85. doi: 10.1042/BST0 330083

Maier, R. J., Benoit, S. L. and Seshadri, S. (2007). Nickel-binding and accessory proteins facilitating Ni-enzyme maturation in Helicobacter pylori. Biometals 20, 655-664. doi: 10.1007/s10534-006-9061-8

Maier, R. J., Fu, C., Gilbert, J., Moshiri, F., Olson, J. and Plaut, A. G. (1996). Hydrogen uptake hydrogenase in Helicobacter pylori. FEMS Microbiol. Lett. 141, 71-76. doi: 10.1111/j.1574-6968.1996.tb08365.x

Mobley, H. L. T., Garner, R. M., Chippendale, G. R., Gilbert, J. V., Kane, A. V. and Plaut, A. G., (1999). Role of Hpn and NixA of Helicobacter pylori in susceptibility and resistance to bismuth and other metal ions. Helicobacter 4, 162-169. doi: 10.1046/j.1523-5378.1999.99286.x

Muller, C., Bahlawane, C., Aubert, S., Delay, C. M., Schauer, K., Michaud-Soret, I., et al. (2011). Hierarchical regulation of the NikR-mediated nickel response in Helicobacter pylori. Nucleic Acids Res. 39, 7564-7575. doi: 10.1093/nar/ gkr460

Musiani, F., Ippoliti, E., Micheletti, C., Carloni, P. and Ciurli, S. (2013). Conformational fluctuations of UreG, an intrinsically disordered enzyme. Biochemistry 52, 2949-2954. doi: 10.1021/bi4001744

Nolan, K. J., McGee, D. J., Mitchell, H. M., Kolesnikow, T., Harro, J. M., O’Rourke, J., et al. (2002). In vivo behavior of a Helicobacter pylori SS1 nixA mutant with reduced urease activity. Infect. Immun. 70, 685-691. doi: 10.1128/IAI.70.2.685691.2002

Olson, J. W. and Maier, R. J. (2002). Molecular hydrogen as an energy source for Helicobacter pylori. Science 298, 1788-1790. doi: 10.1126/science.1077123

Olson, J. W., Mehta, N. S. and Maier, R. J. (2001). Requirement of nickel metabolism proteins HypA and HypB for full activity of both hydrogenase and urease in Helicobacter pylori. Mol. Microbiol. 40, 176-182. doi: 10.1046/j.13652958.2001.02244.x

Romagnoli, S., Agriesti, F. and Scarlato, V. (2011). In vivo recognition of the fecA3 target promoter by Helicobacter pylori NikR. J. Bacteriol. 193, 1131-1141. doi: 10.1128/JB.01153-10

Rowinska-Zyrek, M., Witkowska, D., Bielinska, S., Kamysz, W. and Kozlowski, H. (2011). The -Cys-Cys- motif in Helicobacter pylori's Hpn and HspA proteins is an essential anchoring site for metal ions. Dalton Trans. 40, 5604-5610. doi: $10.1039 / \mathrm{c} 1 \mathrm{dt} 10187 \mathrm{k}$

Sanders, L., Andermann, T. M. and Ottemann, K. M. (2013). A supplemented soft agar chemotaxis assay demonstrates the Helicobacter pylori 
chemotactic response to zinc and nickel. Microbiology 159, 46-57. doi: 10.1099/mic.0.062877-0

Schauer, K. (2007). Étude du Métabolisme du Nickel Chez Helicobacter pylori. PhD dissertation, Université Paris 7 - Denis Diderot, Paris

Schauer, K., Gouget, B., Carriere, M., Labigne, A. and de Reuse, H. (2007). Novel nickel transport mechanism across the bacterial outer membrane energized by the TonB/ExbB/ExbD machinery. Mol. Microbiol. 63, 1054-1068. doi: 10.1111/j.1365-2958.2006.05578.x

Schauer, K., Muller, C., Carriere, M., Labigne, A., Cavazza, C. and De Reuse, H. (2010). The Helicobacter pylori GroES Cochaperonin HspA Functions as a Specialized Nickel Chaperone and Sequestration Protein through Its Unique C-Terminal Extension. J. Bacteriol. 192, 1231-1237. doi: 10.1128/ JB.01216-09

Schauer, K., Rodionov, D. A. and de Reuse, H. (2008). New substrates for TonBdependent transport: do we only see the 'tip of the iceberg'? Trends Biochem. Sci. 33, 330-338. doi: 10.1016/j.tibs.2008.04.012

Seshadri, S., Benoit, S. L. and Maier, R. J. (2007). Roles of His-rich Hpn and Hpn-like proteins in Helicobacter pylori nickel physiology. J. Bacteriol. 189, 4120-4126. doi: 10.1128/JB.01245-06

Sommi, P., Ricci, V., Fiocca, R., Romano, M., Ivey, K. J., Cova, E., et al. (1996). Significance of ammonia in the genesis of gastric epithelial lesions induced by Helicobacter pylori: an in vitro study with different bacterial strains and urea concentrations. Digestion 57, 299-304. doi: 10.1159/000201349

Stahler, F. N., Odenbreit, S., Haas, R., Wilrich, J., Van Vliet, A. H., Kusters, J. G., et al. (2006). The novel Helicobacter pylori CznABC metal efflux pump is required for cadmium, zinc, and nickel resistance, urease modulation, and gastric colonization. Infect. Immun. 74, 3845-3852. doi: 10.1128/IAI.02025-05

Stingl, K. and De Reuse, H. (2005). Staying alive overdosed: how does Helicobacter pylori control urease activity? Int. J. Med. Microbiol. 295, 307-315. doi: 10.1016/j.ijmm.2005.06.006

Stingl, K., Schauer, K., Ecobichon, C., Labigne, A., Lenormand, P., Rousselle, J. C., et al. (2008). In vivo interactome of Helicobacter pylori urease revealed by tandem affinity purification. Mol. Cell Proteom. 7, 2429-2441. doi: 10.1074/mcp.M800160-MCP200

Stoof, J., Kuipers, E. J., Klaver, G. and van Vliet, A. H. (2010a). An ABC transporter and a TonB ortholog contribute to Helicobacter mustelae nickel and cobalt acquisition. Infect. Immun. 78, 4261-4267. doi: 10.1128/IAI.00365-10

Stoof, J., Kuipers, E. J. and van Vliet, A. H. M. (2010b). Characterization of NikR-responsive promoters of urease and metal transport genes of Helicobacter mustelae. Biometals 23, 145-159. doi: 10.1007/s10534-009-9275-7

Suerbaum, S., Thiberge, J.-M., Kansau, I., Ferrero, R. L. and Labigne, A. (1994). Helicobacter pylori hspA-hspB heat-shock gene cluster: nucleotide sequence, expression, putative function and immunogenicity. Mol. Microbiol. 14, 959-974. doi: 10.1111/j.1365-2958.1994.tb01331.x
Volbeda, A., Charon, M. H., Piras, C., Hatchikian, E. C., Frey, M. and FontecillaCamps, J. C. (1995). Crystal structure of the nickel-iron hydrogenase from Desulfovibrio gigas. Nature 373, 580-587. doi: 10.1038/373580a0

Williams, C. L., Preston, T., Hossack, M., Slater, C. and McColl, K. E. L. (1996). Helicobacter pylori utilises urea for amino acid synthesis. FEMS Immunol. Med. Microbiol. 13, 87-94. doi: 10.1111/j.1574-695X.1996.tb00220.x

Wolfram, L., Haas, E. and Bauerfeind, P. (2006). Nickel represses the synthesis of the nickel permease NixA of Helicobacter pylori. J. Bacteriol. 188, 1245-1250. doi: 10.1128/JB.188.4.1245-1250.2006

Wroblewski, L. E., Peek, R. M. J. and Wilson, K. T. (2010). Helicobacter pylori and gastric cancer: factors that modulate disease risk. Clin. Microbiol. Rev. 23, 713-739. doi: 10.1128/CMR.00011-10

Xia, W., Li, H., Yang, X., Wong, K. B. and Sun, H. (2012). Metallo-GTPase HypB from Helicobacter pylori and its interaction with Nickel chaperone protein HypA. J. Biol. Chem. 287, 6753-6763. doi: 10.1074/jbc.M111.287581

Zambelli, B., Stola, M., Musiani, F., De Vriendt, K., Samyn, B., Devreese, B., et al. (2005). UreG, a chaperone in the urease assembly process, is an intrinsically unstructured GTPase that specifically binds Zn. J. Biol. Chem. 280, 4684-4695. doi: 10.1074/jbc.M408483200

Zambelli, B., Turano, P., Musiani, F., Neyroz, P. and Ciurli, S. (2009). $\mathrm{Zn}^{2+}$-linked dimerization of UreG from Helicobacter pylori, a chaperone involved in nickel trafficking and urease activation. Proteins 74, 222-239. doi: 10.1002/prot.22205

Zeng, Y. B., Zhang, D. M., Li, H. Y. and Sun, H. Z. (2008). Binding of $\mathrm{Ni}^{2+}$ to a histidine- and glutamine-rich protein, Hpn-like. J. Biol. Inorg. Chem. 13, 1121-1131. doi: 10.1007/s00775-008-0397-0

Zeng, Y., Yang, N. and Sun, H. (2011). Metal-binding properties of an Hpn-like histidine-rich protein. Chem. Eur. J. 17, 5852-5860. doi: 10.1002/chem.201100279

Conflict of Interest Statement: The authors declare that the research was conducted in the absence of any commercial or financial relationships that could be construed as a potential conflict of interest.

Received: 16 October 2013; paper pending published: 01 November 2013; accepted: 21 November 2013; published online: 09 December 2013.

Citation: de Reuse H, Vinella D and Cavazza C (2013) Common themes and unique proteins for the uptake and trafficking of nickel, a metal essential for the virulence of Helicobacter pylori. Front. Cell. Infect. Microbiol. 3:94. doi: 10.3389/fcimb.2013.00094 This article was submitted to the journal Frontiers in Cellular and Infection Microbiology.

Copyright (c) 2013 De Reuse, Vinella and Cavazza. This is an open-access article distributed under the terms of the Creative Commons Attribution License (CC BY). The use, distribution or reproduction in other forums is permitted, provided the original author(s) or licensor are credited and that the original publication in this journal is cited, in accordance with accepted academic practice. No use, distribution or reproduction is permitted which does not comply with these terms. 